\title{
Positive and Negative Curiosity Experiences Among Tertiary Students
}

\author{
David Palmer \\ School of Education, University of Newcastle, \\ New South Wales, 2308, Australia \\ E-mail: David.Palmer@newcastle.edu.au
}

Received: May 30, 2018

Accepted: June 13, 2018

Published: June 20, 2018

doi:10.5296/gjes.v4i1.13226

URL: https://doi.org/10.5296/gjes.v4i1.13226

\begin{abstract}
Curiosity is a motivation construct that is important at all levels of education. This study investigated the curiosity experiences of tertiary students. Individual interviews were carried out with 20 tertiary students. Participants were asked to describe experiences of wanting-to-learn (positive curiosity) or not-wanting-to-learn (negative curiosity) that they had recently experienced in regular classes. Participants reported they had recently experienced both forms of curiosity, which correlated with high and low levels of cognitive learning behaviours. Antecedent factors included personal interest, confidence, expectancies, value, and teacher influences.
\end{abstract}

Keywords: Curiosity, Interest, Expectancies, Value 


\section{Introduction}

Curiosity has been identified as an attribute that should be encouraged at all levels of education (Murphy \& Martin, 2015), and in recent years, curiosity has been studied among middle school students (e.g., Luce \& Hsi, 2014), high school students (e.g., Zhao, Lu, Wang, \& Huang, 2011), and tertiary students (e.g., Metcalfe, Schwartz, \& Bloom, 2017).

One issue is that curiosity is a "fuzzy" construct, not only because it is a term widely used in everyday life, and often without clear definition, but also because it comprises a number of interrelated cognitive, affective, and behavioural dimensions (Grossnickle, 2016). Thus, a person might claim to have experienced curiosity, but the true nature of the cognitive/affective/behavioural experience is open to question. As researchers, it is important that we clearly identify the phenomenon that is being investigated. For this reason, the present study has a focus on the cognitive dimension of curiosity-the desire to learn-which is arguably the most defining feature of this construct.

\section{Theoretical Framework}

The essence of curiosity is a desire to learn. Berlyne (1960) for example, proposed that curiosity occurs when a person's interaction with the environment results in a search for knowledge. Similarly, Litman (2005) defined curiosity as "a desire to know, to see, or to experience that motivates exploratory behaviour directed towards the acquisition of new information" (p. 793). Other authors have variously defined it as "the desire for information" (Kidd \& Hayden, 2015, p. 449), the need "to seek new information and new sensory experiences" (Próchniak, 2017, p. 1246), and "the desire to know" (Noordewier \& van Dijk, 2017, p. 411). Although these definitions differ in detail, they are similar in that they emphasise an urge to obtain knowledge, a phenomenon that has been referred to as cognitive curiosity or epistemic curiosity (Berlyne, 1960; Reio Jr., Petrosko, Wiswell, \& Thongsukmag, 2006).

Curiosity is important because it is a powerful motivator in educational settings. It stimulates behaviour that is directed towards the acquisition of new information (Berlyne, 1960; Reio Jr. et al., 2006), and there is typically high concentration and attention focused on the source of information (Schmitt \& Lahroodi, 2008). The review by Grossnickle (2016) concluded that curiosity enhances memory for new information and has been linked to higher academic performance.

Curiosity has also been framed as either a trait or a state. Trait curiosity is a long-term characteristic that makes some individuals more generally curious than others, whereas state curiosity is an episodic form that results from environmental triggers (Litman, Hutchins, \& Russon, 2005). State curiosity is particularly interesting because it is the curiosity that dominates our consciousness from time to time, when we feel a strong sensation of wanting to understand material that is currently being made available. However, the previous studies of curiosity have typically focused on trait rather than state (Grossnickle, 2016). Thus, relatively little is known about the characteristics and antecedents of state curiosity experiences. For this reason, it was decided to focus the present study on student reports of 
situations when they were actively experiencing curiosity.

A large number of antecedents of curiosity have been identified. Arnone, Small, Chauncey, and McKenna (2011) stated that curiosity could be influenced by factors such as perceptions of value, expectancies of success, self-efficacy beliefs, and social influences. Other causative factors have been proposed, including collative stimuli such as novelty and complexity (Engel, 2011), the anticipated enjoyment and pleasure that accompanies the learning of new information (Litman, 2005), teacher support (Zhao, Lu, Wang, \& Huang, 2011), perceived ability to comprehend the information (Silvia, 2008), and personal interest (Schmitt \& Lahroodi, 2008). However, the relative importance of each of these for students at different levels of education has not yet been established.

There are reasons to believe that tertiary students might experience relatively high levels of curiosity. Some researchers have been concerned about the apparent lack of curiosity among students in primary and secondary schools (Archer et al., 2016; Engelhard Jr. \& Monsaas, 1988). Others have reported that curiosity among school students may be dependent on the extent to which the school culture supports curiosity and exploration (Kashdan \& Yuen, 2007). By contrast, Schmitt and Lahroodi (2008) argued that curiosity might revive when students enter university. These authors argued that tertiary students have the opportunity to choose programs of study that align with their personal interests, so their curiosity is likely to be aroused when they encounter content that is relevant to those interests. The purpose of the present study is to investigate the characteristics and antecedents of curiosity experiences among tertiary students.

\section{The Present Study}

In this paper, the term "curiosity experiences" will be used to refer to occasions on which students actively experience the desire to learn material that is currently being made available. The aims of the study were:

(1) To investigate the characteristics of curiosity experiences among tertiary students in regular lessons;

(2) To investigate the antecedents of curiosity experiences among tertiary students.

\section{Method}

A comparative design was used (McMillan \& Schumacher, 2006). Data collection was by individual interview with 20 tertiary students. Triangulation was used to establish validity and reliability.

\subsection{Participants}

The participants comprised 20 students, who were in their final year of an undergraduate teacher education program in a regional city in Australia. Most were in the 20-30-years age group, and the gender ratio was $45 \%$ male to $55 \%$ female. The students were volunteers who were recruited by a general request to all students in the course to contact the interviewer by email if they wished to be interviewed. None of the students were previously known to the 
interviewer.

As all the participants self-selected for this study, it raised the possibility that they may have been more highly curious than the other students. This did not appear to be the case though, because as will be shown in the results, the participants reported almost as many negative experiences as there were positive.

\subsection{Data Collection and Validity}

Interview was chosen as the data collection technique because it would allow participants to describe the nature of their experiences in their own words. The interview schedule was developed from pilot interviews with four students who were not included in the final study. In the study itself, each interview lasted about 30 minutes and was audiorecorded for transcription.

At the beginning of the interview, each participant was asked to bring to mind a recent lecture (i.e., from the previous two/three days) in which he/she had experienced a strong feeling of wanting-to-learn or not-wanting-to-learn (the pilot interviews had indicated that students could also experience a negative form of cognitive curiosity-not-wanting-to-learn-so this option was included). Interviewees were asked to use their experiences from that lesson to answer the interview questions. The guide questions for Aim 1 were:

(1) Did you get a feeling that you did want to learn or didn't want to learn in that lecture? Please explain.

(2) When did that feeling start?

(3)When you had that feeling of wanting-to-learn (or not-wanting-to-learn) were you concentrating, and/or thinking about the work? Please explain.

For Aim 2, participants were shown the Factor List (Table 1) and were asked,

(4) Did any of these influence your feeling of wanting-to-learn (or not-wanting-to-learn)? Participants were asked to indicate whether each item had been a Main factor, Moderate factor, Small factor, or Not a factor in helping to make that feeling.

(5) Of the factors that did influence you, would each have been positive or negative in its effect?

Long and Johnson (2000) stated that triangulation can be carried out using responses from a single interview, by asking different types of questions and comparing the extent to which the responses remain concordant. In this way, construct validity for the curiosity experience (Aim 1) was established by triangulating responses from Questions 1, 2, and 3. Internal validity of the causal factors (Aim 2) was triangulated by comparing responses from Questions 4 and 5. Reliability was a less important consideration for this study, because it cannot be assumed that a person's experience of curiosity on one occasion will be equivalent to that on another occasion. 


\section{Macrothink}

Global Journal of Educational Studies

ISSN 2377-3936

2018, Vol. 4, No. 1

Table 1 . The factor list used to identify antecedents of the curiosity experience

\begin{tabular}{|l|l|l|l|l|}
\hline Item & $\begin{array}{c}\text { Main } \\
\text { Factor }\end{array}$ & $\begin{array}{c}\text { Moderate } \\
\text { Factor }\end{array}$ & $\begin{array}{c}\text { Small } \\
\text { Factor }\end{array}$ & $\begin{array}{c}\text { Not A } \\
\text { Factor }\end{array}$ \\
\hline 1.* your level of confidence for this subject & & & & \\
\hline 2. your personal level of interest in this topic & & & & \\
\hline 3. whether you expected to really understand & & & & \\
\hline 4. whether you valued this subject & & & & \\
\hline 5. what the other students would think about you & & & & \\
\hline 6. what your parents would want you to do & & & & \\
\hline 7. whether you liked the teacher & & & & \\
\hline $\begin{array}{l}\text { 8. whether you expected to enjoy the lesson and get a } \\
\text { good feeling }\end{array}$ & & & & \\
\hline $\begin{array}{l}\text { 9. whether you expected the lesson to be interesting } \\
\text { or boring }\end{array}$ & & & & \\
\hline 10. whether you were tired & & & & \\
\hline
\end{tabular}

* The items were not numbered in the version shown to students. The items were randomised and regularly rotated throughout the study.

\subsection{Data Analysis}

Inductive thematic analysis (Braun \& Clarke, 2006) was used to code the students' responses to each question. After reading the transcripts, responses that seemed to express the same idea were organised into categories that were directed by the content of the data. To determine inter-rater reliability, the interviewer and a co-coder independently categorised a representative sample of 38 responses, and agreement was found in $87 \%$ of cases.

The quantitative analyses used numerical scores that were assigned for different categories of response, as will be explained in each section of the results.

\section{Results}

\subsection{Responses to Question 1}

Fifty percent of the participants stated they had experienced a strong feeling of wanting-to-learn in a recent lesson, so they were categorised as having experienced a positive curiosity experience. For example:

- I'd say it was a feeling of curiosity and sort of enhanced interest in the material. (male)

- Definitely a feeling of wanting to be there and wanting to learn ... I'm keen, I'm eager, I want to do that. (female)

On the other hand, $40 \%$ of participants described a lesson in which they had experienced a feeling of not-wanting-to-learn. These were categorised as representing a negative curiosity experience. For example: 
- When I found out what we were going to be learning about I felt like I didn't need to be there. I didn't want to learn that stuff. (male)

- It was something that I knew very little about, but I didn't feel I wanted to extend on that knowledge. (female)

The remaining students, comprising $10 \%$ of the participants, gave responses that were not clear. As these four individuals could not be reliably categorised they were excluded from further analysis. The remainder of this paper will include responses only from the 18 participants whose responses could be reliably categorised.

Fisher exact probability tests (which can be used instead of chi-square when some cells contain numbers less than 5) were used to check whether positive or negative cognitive curiosity was related to gender, but no significant difference was found $(p=.1534)$.

\subsection{Responses to Question 2}

In response to Question 2, 83\% of participants reported that the cognitive curiosity experience (positive or negative) had started very close to the beginning of the lesson, which implied it was not the continuation of an ongoing predisposition, but instead was indicative of an episodic phenomenon. For example:

- I already had an idea that it wasn't going to be a very interesting tutorial, so [it started] probably just before. I already had an idea about it. (female, negative curiosity)

- I'd say it happened when the name of the actual theory came out, because the name was connecting to other things we were doing, and that was what switched me on. (male, positive curiosity)

\subsection{Responses to Question 3}

Responses to this question were categorised as either high concentration/thinking or low concentration/thinking. The following are examples (cognitive behaviours italicised):

- I guess just the willingness to concentrate and pay attention and try to comprehend the information. Probably relating it to my own personal experiences and how I can apply that knowledge and compare it to previous things that we had learnt in that particular subject. (categorized as high concentration/thinking)

- I would say I did focus on her, but nothing went into my mind. (categorized as low concentration/thinking)

For quantitative analysis, concentration/thinking was scored as either 2 (high) or 1 (low) for each student. Each student was also scored as either 2 (wanting-to-learn) or 1 (not-wanting-to-learn). Using these data, Pearson correlation tests were carried out to compare cognitive curiosity with concentration/thinking. Strong, positive correlations were found, $r(18)=0.85, p<.001$. This indicated that positive wanting-to-learn went with high levels of concentration/thinking, whereas not-wanting-to-learn went with low concentration/thinking. 


\section{Macrothink}

Global Journal of Educational Studies

ISSN 2377-3936 2018, Vol. 4, No. 1

Correlations by themselves do not establish causality, so the students' explanatory statements were also examined. These provided evidence that the feelings of wanting-to-learn or not-wanting-to-learn may have provided an impetus for the activation or non-activation of cognitive learning behaviours (none of the explanations suggested the relationship went the other way). For example, the quotes below imply this type of relationship (italics inserted for emphasis):

- The feeling is like an internal thing . . but the product of that feeling is paying attention and being able to demonstrate some understanding. (male, positive curiosity)

- It definitely made me zone out. I'll admit that I probably wasn't paying much attention whatsoever. I wasn't engaged at all. Had no desire to learn the content. (female, negative curiosity)

In summary, responses to Questions 1, 2, and 3 triangulated well, because they all provided evidence for positive and negative cognitive curiosity experiences that were episodic in nature. This suggested an acceptable level of validity for the positive and negative valence of the cognitive curiosity experience.

\subsection{Responses to Question 4}

Every participant in this study indicated that several of the items shown in Table 1 had influenced the feeling of wanting-to-learn or not-wanting-to-learn. On average, the participants selected 1.3 Main factors, 2.7 Moderate factors, and 2.6 Small factors. However, there was much variation between individuals as to the specific factors they selected, and it should be noted that every item in Table 1 was identified as an antecedent by at least one participant.

For quantitative analysis, each Main factor was allocated a score of 3, Moderate factors were scored as 2, Small factors were scored as 1 , and Not factors were scored 0 . Using these scores, one-way analyses of variance were used to compare the effect of each factor. A highly significant difference was found: $F(9,18)=6.9688, p<.05$. Tukey HSD post hoc tests showed that Item 5 (other students) and Item 6 (parents) had significantly less influence than the other factors.

The Main factors were assumed to have the most influence. Figure 1 shows the frequency with which each item was chosen as a Main factor. It shows that Item 2 (personal interest) was selected with highest frequency, whereas Item 5 (other students) and Item 6 (parents) were selected least frequently. 


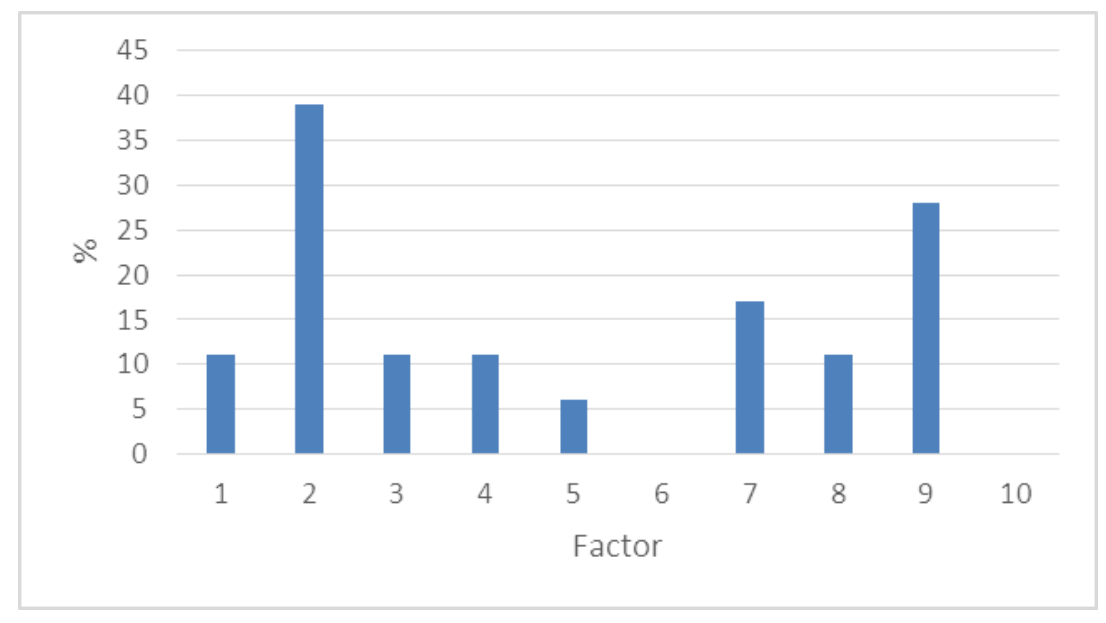

Figure 1. Frequency of main factors

Note. Factors: $1=$ self-efficacy, $2=$ personal interest, $3=$ expectancies of success, $4=$ value, $5=$ students, $6=$ parents, $7=$ teacher, $8=$ expected enjoyment, $9=$ interestingness, $10=$ fatigue.

As Item 2 (personal interest) was most frequently selected as the Main factor of influence, Fisher exact probability tests were carried out to check for gender with respect to this item. However, no significant gender differences were found $(p=1)$.

\subsection{Responses to Question 5}

In response to Question 5, participants indicated whether each of the factors that influenced them had been positive or negative in its effect. For example, Item 1 (confidence) was coded as positive if the participant indicated he/she had been confident, but was coded as negative if not confident. Most participants (78\%) reported that some factors had been positive and others negative, whereas the remainder reported only positive influences.

For analysis, each item was scored as either 3 (Main factor), 2 (Moderate factor), 1 (Small factor), or 0 (Not a factor), and each was also scored as either positive or negative, as indicated by the participant. For example, if Item 1 (confidence) had been a Moderate factor with a positive influence it was scored as +2 for that person. Then, each participant's scores for all the items were summed, to obtain an individual total that was either positive or negative (no zero totals were found). Positive totals were given a final score of 2, whereas negative totals were scored as 1. These were compared to the responses from Question 1, which had been scored as either 2 (wanting-to-learn) or 1 (not-wanting-to-learn). Pearson correlation tests showed positive correlations, $r(18)=0.8944, p<.001$. This indicated that a predominance of weighted positive factors among the antecedents went with positive curiosity experiences, whereas a predominance of weighted negative factors among the antecedents went with negative curiosity experiences. This analysis provided additional evidence of a possible causal link between the items in the Factor List and the curiosity experience.

In summary, responses to Questions 4 and 5 triangulated well because each suggested that the 
items in Table 1 were potential antecedents of the curiosity experience, although not all factors applied to each individual.

\section{Discussion}

\subsection{Aim 1: Characteristics of the Curiosity Experience}

The most striking finding in relation to Aim 1 was that there were positive and negative forms of curiosity experience. The positive form was represented by a feeling of wanting-to-learn, whereas the negative form was a feeling of not-wanting-to-learn. The finding that curiosity experiences were valenced in this way was unexpected, because previous definitions of curiosity have emphasized knowledge-seeking rather than knowledge-avoidance (Grossnickle, 2016). In one exception however, Perlovsky, Bonniot-Cabanac, and Cabanac (2010) asked adult men and women about their curiosity to learn information such as "Do you know the criteria used to rank restaurants?" and these authors used the term "negative curiosity" in cases when participants rejected the opportunity to learn the information. More recently, Karliner (2016) studied curiosity among psychotherapy patients and reported that in some instances they reported a "wish to know" whereas in other instances they reported "the wish not to know". These two studies appear to parallel the type of negative curiosity experience identified in the present study.

As the present study has provided evidence for the negative form of cognitive curiosity, it raises the question of why it has not been more widely recognised in previous studies. One possible explanation is that previous measurements of curiosity have typically focused on ongoing predispositions (traits) rather than episodic experiences (Grossnickle, 2016). This is an important distinction, because a history student (for example) could have an ongoing predisposition to want to learn about history, but there might be particular occasions in which he/she might experience a feeling of not-wanting-to-learn, due to situational factors such as fatigue. This episodic state of mind would therefore not represent his/her normal approach to studies in history.

The negative curiosity experience was important because it was so common, being described by roughly $40 \%$ of participants. This is a very serious issue, because responses to Question 3 indicated that when students were not-wanting-to-learn they typically reported a lack of cognitive learning behaviours. This might be expected to negatively affect the amount of learning occurring at these times. The relatively high proportion of participants who had recently experienced this phenomenon was cause for concern, and suggests that this issue needs to be urgently addressed.

\subsection{Aim 2: Antecedents of the Cognitive Curiosity Experience}

Most participants indicated that the majority of the factors shown in Table 1 had contributed to the arousal of cognitive curiosity, but there was much variation between individuals as to the specific factors they selected. Participants typically identified one or two Main factors, and other factors were identified as Moderate or Small. This suggested that, for each individual, some factors may have had more influence than others. This is reminiscent of the idea of a hierarchy of antecedents, which has been invoked in some other education 
constructs (e.g., Kek \& Huijser, 2011), but the present study has suggested that the curiosity experience may also, on occasion, be derived from a hierarchy of antecedents.

The idea of a hierarchy of antecedents implies that there must be an appraisal of that hierarchy in order to determine the combined effect of all the factors. Analysis of the responses to Question 5 suggested that a predominance of weighted positive factors (e.g., high confidence, high personal interest, high expectations of understanding and enjoying the lesson, high value of the content, and low fatigue) among the antecedents predicted a positive curiosity experience, whereas a predominance of weighted negative factors (e.g., low confidence, low personal interest, low value, and high fatigue) predicted a negative curiosity experience. Thus, the process that creates the valence of the curiosity experience might be modelled as a comparison of the amounts of "positiveness" and "negativeness" in the antecedent hierarchy at any given time.

The most commonly selected Main factor was personal interest in the content (Item 2). This appears to support the case put forward by Schmitt and Lahroodi (2008), who argued that adult humans develop special interests, and that curiosity in adults is closely aligned to the knowledge areas that relate to those interests. However, as shown in Figure 2, there were many participants who did not nominate personal interest as a Main factor. In fact, seven of the other nine items, including confidence, expectations of understanding, value, liking the teacher, expecting to enjoy the lesson, and expecting the lesson to be interesting/boring, were selected as the Main factor by other participants. The implication here is that there was much individual variation as to the main cause of their curiosity experience.

\section{Conclusions and Implications}

This study has provided evidence about the characteristics and antecedents of curiosity experiences of tertiary students. Some of the findings of the study should provide avenues for further research. For example, it was found that many participants had recently experienced the negative form of curiosity. At these times, students reported little or no concentration upon the material being presented. It would therefore be important to investigate how often this type of situation occurred during their studies and to identify strategies that could reduce the problem.

This problem of the apparently widespread occurrence of the negative cognitive curiosity experience also has an important educational implication. Analysis indicated that at these times, the individuals were experiencing a predominance of negative factors among the antecedents: low expectations, low personal interest, low value, and high fatigue, for example. This suggests that teachers should make every effort to ensure that these factors are established and maintained at positive rather than negative levels. For example, by continually emphasising the interesting aspects of the content, how the material will be valuable to them in the future and by monitoring the need for breaks to reduce learning fatigue.

\section{References}

Archer, L., Dawson, E., DeWitt, J., Godec, S., King, H., Mau, A, Nomikou, E., \& Seakins, A. 
(2016). Killing curiosity? An analysis of celebrated identity performances among teachers and students in nine London secondary science classrooms. Science Education, 101, 741-764. https://doi.org/10.1002/sce.21291

Arnone, M. P., Small, R. V., Chauncey, S. A., \& McKenna, H. P. (2011). Curiosity, interest and engagement in technology-pervasive learning environments: A new research agenda. Educational Technology Research and Development, 59, 181-198. https://doi.org/10.1007/s11423-011-9190-9

Berlyne, D. E. (1960). Conflict, arousal, and curiosity. New York, NY: McGraw-Hill.

Braun, V., \& Clarke, V. (2006). Using thematic analysis in psychology. Qualitative Research in Psychology, 3, 77-101.

Engel, S. (2011). Children's need to know: Curiosity in schools. Harvard Educational Review, $81,625-645$.

Engelhard, G. Jr., \& Monsaas, J. A. (1988). Grade level, gender, and school-related curiosity in urban elementary schools. Journal of Educational Research, 82, 22-26.

Grossnickle, E. M. (2016). Disentangling curiosity: Dimensionality, definitions, and distinctions from interest in education contexts. Educational Psychology Review, 28, 23-60. https://doi.org/10.1007/s10648-014-9294-y

Karliner, R. (2016). The wish to know/the wish not to know: Curiosity and the primal scene. $\begin{array}{lllll}\text { Studies in } \text { Gender and } & \text { Sexuality, } 211 .\end{array}$ https://doi.org/10.1080/15240657.2016.1199932

Kashdan, T. B., \& Yuen, M. (2007). Whether highly curious students thrive academically depends on perceptions about the school learning environment: A study of Hong Kong $\begin{array}{llll}\text { adolescents. } \quad \text { Motivation } & \text { Emotion, 260-270. }\end{array}$ https://doi.org/10.1007/s11031-007-9074-9

Kek, M., \& Huijser, H. (2011). Exploring the combined relationships of student and teacher factors on learning approaches and self-directed learning readiness at a Malaysian university. Studies in Higher Education, 36, 185-208. https://doi.org/10.1080/03075070903519210

Kidd, C., \& Hayden, B. H. (2015). The psychology and neuroscience of curiosity. Neuron, 88, November. https://doi.org/10.1016/j.neuron.2015.09.010

Litman, J. A. (2005). Curiosity and the pleasures of learning: Wanting and liking new $\begin{array}{lllll}\text { information. Cognition } \quad \text { and } & \text { Emotion, }\end{array}$ https://doi.org/10.1080/02699930541000101

Litman, J. A., Hutchins, T. L., \& Russon, R. K. (2005). Epistemic curiosity, feeling-of-knowing, and exploratory behavior. Cognition and Emotion, 19, 559-582. https://doi.org/10.1080/02699930441000427

Long, T., \& Johnson, M. (2000). Rigor, reliability and validity in qualitative research. Clinical Effectiveness in Nursing, 4, 30-37. 


\section{Mll Macrothink}

Global Journal of Educational Studies ISSN 2377-3936 2018, Vol. 4, No. 1

Luce, M. R., \& His, S. (2015). Science-relevant curiosity expression and interest in science: An exploratory study. Science Education, 99, 70-97. https://doi.org/10.1002/sce.2144

McMillan, J. H., \& Schumacher, S. (2006). Research in Education: Evidence-based inquiry. Boston: Pearson.

Metcalfe, J., Schwartz, B. L., \& Bloom, P. A. (2017). The tip-of-the-tongue state and curiosity. Cognitive Research: Principles and Implications, $2, \quad 31$. https://doi.org/10.1186/s41235-017-0065-4

Murphy, C., \& Martin, S. N. (2015). Coteaching in teacher education: Research and practice. Asia-Pacific Journal of Teacher Education, 43, 277-280. https://doi.org/10.1080/1359866X.2015.1060927

Noordewier, M. K., \& van Dijk, E. (2017). Curiosity and time: From not knowing to almost knowing. Cognition and Emotion, 31, 411-421. https://doi.org/10.1080/02699931.2015.1122577

Perlovsky, L., Bonniot-Cabanac, M. C., \& Cabanac, M. (2010). Curiosity and pleasure. Retrieved from https://arxiv.org/abs/1010.3009

Próchniak, P. (2017). Development and testing of the elements of the nature curiosity scale. Social Behavior and Personality, 45, 1245-1254. https://doi.org/10.2224/sbp.6130

Reio Jr., T. G., Petrosko, J. M., Wiswell, A. K., \& Thongsukmag, J. (2006). The measurement and conceptualization of curiosity. The Journal of Genetic Psychology, 167, 117-135.

Schmitt, F. F., \& Lahroodi, R. (2008). The epistemic value of curiosity. Educational Theory, $58,125-148$.

Schunk, D. H. (2004). Learning theories: An educational perspective. Upper Saddle River, NJ: Pearson Prentice Hall.

Silvia, P. J. (2008). Appraisal components and emotion traits: Examining the appraisal basis of trait curiosity. Cognition and Emotion, 22, 94-113. https://doi.org/10.1080/02699930701298481

Zhao, L., Lu, Y., Wang, B., \& Huang, W. (2011). What makes them happy and curious online? An empirical study of high school students' internet use from a self-determination theory perspective. Computers \& Education, 56, 346-356.

\section{Copyright Disclaimer}

Copyright for this article is retained by the author(s), with first publication rights granted to the journal.

This is an open-access article distributed under the terms and conditions of the Creative Commons Attribution license (http://creativecommons.org/licenses/by/3.0/). 